\title{
COMPARISON OF EFFECTS OF ORAL MATERNAL HYDRATION AND INTRAVENOUS INFUSIONS ON AMNIOTIC FLUID INDEX IN THIRD TRIMESTER ISOLATED OLIGOHYDRAMNIOS.
}

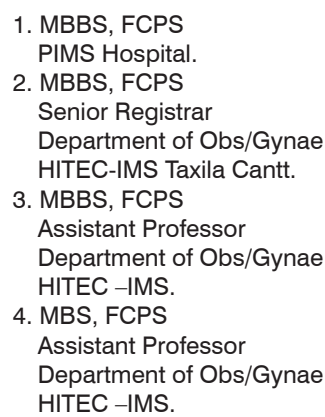

Correspondence Address:

Dr. Adeela Ameen

E2, AERO, Lapthattu

Haripur Hazar Road, Hassanabdal.

adeela008@gmail.com

Article received on: 02/04/2018

Accepted for publication:

23/05/2019

\begin{abstract}
Saima Kiran', Adeela Ameen², Ayesha Akram³ ${ }^{3}$ Mahwash Jamil ${ }^{4}$
\end{abstract}
\begin{abstract}
Objectives: To compare oral maternal hydration and intravenous infusion in women with third trimester isolated oligohydramnios in terms of mean change in amniotic fluid. Study Design: This is a Comparative Study. Setting: The study was conducted in Department of Gynecology, Pakistan Institute of Medical Sciences, Islamabad. Period: Between $1^{\text {st }}$ May, 2015 to $31^{\text {st }}$ July, 2016. Material \& Methods: One hundred and fourteen pregnant females with singleton pregnancy, beyond 28 weeks gestation and AFI $<5 \mathrm{~cm}$ were included. Placental insufficiency was ruled out on Doppler ultrasound of umbilical artery. Basal AFI and routine intake of fluid of all patients was noted. Patients were randomized either to receive oral maternal hydration or intravenous infusion. AFI measurement was repeated at 6th day after hydration therapy. Data was stratified for mean difference in improvement in amniotic fluid index. Results: One hundred and fourteen patients with mean age of $27.33 \pm 3.87$ years were included. 52 patients $(45.6 \%)$ were primigravida and remaining 62 patients $(54.4 \%)$ were multipara. Mean AFI value before treatment in sampled population was $3.35 \pm 0.744$ in oral hydration and 3.33 \pm 0.787 in intravenous hydration $(p=0.903)$. Mean AFI value after treatment was $5.53 \pm 0.966$ in oral hydration and $5.68 \pm 1.490$ in intravenous hydration, independent sample test showed non-significant $(p=0.903)$ difference. Mean increase in AFI before and after treatment was cross tabulated and resultant difference was significant ( $p$ value $=0.001$ ). There is no effect of age, gestational age, history of oligohydramnios on improvement in amniotic fluid index. Conclusion: Both treatment modalities i.e. oral maternal hydration and intravenous infusion are effective in terms of improvement of amniotic fluid index but there is no difference in both treatments in pregnant females with isolated oligohydramnios in $3^{\text {rd }}$ trimester at current sample size.
\end{abstract}

Key words: Amniotic Fluid Index, Intravenous Hydration, Isolated Oligohydramnios, Oral Hydration.

Article Citation: Kiran S, Ameen A, Akram A, Jamil M. Comparison of effects of oral maternal hydration and intravenous infusions on Amniotic Fluid Index in third trimester isolated Oligohydramnios. Professional Med J 2019; 26(12):20642069. DOI: 10.29309/TPMJ/2019.26.12.3049

\section{INTRODUCTION}

Amniotic fluid is a clear fluid that is present in amniotic sac and surrounds the fetus. Amnion, fetal skin, umbilical cord, kidneys and lungs contribute in the formation of amniotic fluid at different stages of fetal life and is removed by fetal swallowing. The amniotic fluid volume progressively increases to $1000 \mathrm{ml}$ by 38 weeks gestation and decreases thereafter to reach 350 $\mathrm{ml}$ by 42 weeks. ${ }^{1}$

Amniotic fluid volume is measured by amniotic fluid index (AFI) and maximum vertical pool (MVP). AFI is an ultrasound estimation of amniotic fluid derived by adding together the deepest vertical pools, free of fetal parts, in four uterine quadrants. ${ }^{2}$ Many factors may affect the amniotic fluid index including maternal blood volume, hydration status and maternal plasma osmolality. ${ }^{3}$

Oligohydramnios is defined as amniotic fluid index less than $5^{\text {th }}$ centile for gestation, ${ }^{2,4}$ or an amniotic fluid index $<5 \mathrm{~cm}$ or no pocket of amniotic fluid $\geq 2 \mathrm{~cm} .{ }^{5}$ It is found in about $1-5 \%$ of the pregnancies. ${ }^{3}$ Adequate amniotic fluid allows normal fetal movements and growth and cushions the fetus and umbilical cord. Oligohydramnios may inhibit these processes and can lead to fetal 
limb defects, pulmonary hypoplasia, IUGR, cord compression, fetal distress, operative deliveries, meconium aspiration and stillbirth. ${ }^{4,6,7}$

Oligohydramnios may be caused by fetal urinary tract abnormalities, uteroplacental insufficiency, fetal growth restriction, various drugs and rupture of membranes. ${ }^{7,8}$

Many studies have reported an increase in amniotic fluid index with maternal hydration in normal pregnancies and in pregnancies with oligohydramnios. Shahnazi et al. reported an increase in amniotic fluid index (from 4.70 to $6.25 \mathrm{~cm}$ ) after hydration with one liter of isotonic saline infusion. ${ }^{3}$ However, in a recent Cochrane review, Hofmeyr et al. reported an increase in amniotic volume with oral (MD 1.35,95\% confidence interval (Cl) 1.43 to 2.60 ) as well as intravenous hypotonic hydration (MD 1.35, 95\% $\mathrm{Cl} 0.61$ to 2.10), but no measureable effects were seen with intravenous isotonic hydration (MD $1.35 .95 \% \mathrm{Cl}-0.67$ to 0.67$).{ }^{6}$

A study by Momina et al. compared oral and intravenous hydration in third trimester oligohydramnios and recorded an amniotic fluid index $7.48 \pm 0.303$ in oral group and $5.89 \pm 0.373$ in intravenous group after hydration. ${ }^{4}$ Qureshi and Yusuf studied the effect of intravenous amino acid solution in isolated oligohydramnios and found it to be an effective therapy in raising AFI from mean pre-infusion $\mathrm{AFI}$ of $4.7 \mathrm{~cm}$ to $5.8 \mathrm{~cm}$ mean one week post infusion. ${ }^{8}$

There is a lack of trials which have compared oral maternal hydration with intravenous infusions (intravenous amino acids and Hartmann's solution) in isolated oligohydramnios. The current study is performed to assess the effectiveness of oral hydration versus intravenous infusion in improving AFI whereby clarifying the role of these interventions in isolated oligohydramnios.

\section{METHODOLOGY}

The study was conducted in Department of Gynecology, Pakistan Institute of Medical Sciences, Islamabad, between $1^{\text {st }}$ May, 2015 to $31^{\text {st }}$ July, 2016. We randomly selected
114 patients in third trimester with isolated oligohydramnios (where maternal or fetal cause of oligohydramnios is not evident). The patients were recruited through OPD after taking written consent. Approval from our institute's Ethics Committee was obtained for the study.

Patients aged 20-40 years with singleton pregnancy more than 28 weeks gestation, with AFI less than $5 \mathrm{~cm}$ were included. Exclusion criteria were premature rupture of membranes, antepartum hemorrhage, post-term pregnancy, congenital anomalies, multiple pregnancy, intrauterine growth restriction, labour, severe maternal comorbidites (pre-eclampsia, eclampsia, cardiovascular disorders, etc).

We calculated AFI according to the method of Phelan et $\mathrm{al}^{9}$, which added the maximum vertical fluid pocket (free of cord and fetal parts) taken in 4 uterine quadrants. AFI measurement was done by a single sonographer to avoid interobserver variability.

All study related information were collected on a pre-designed proforma. Demographic history was taken. Basal AFI and routine intake of fluid of all patients was noted. Placental insufficiency was ruled out on Doppler ultrasound of umbilical artery. By probability sampling technique patients were divided into two groups. Fifty seven patients in group A received treatment with 1.5 liters of oral fluids i.e. water, juices and tea and a similar number in group $B$ received treatment with $500 \mathrm{ml}$ of intravenous amino acids (Panamin-G) and $1000 \mathrm{ml}$ of Hartmann's solution daily for 6 days, in addition to their normal routine fluid intake. The hydration therapy was carried out in daycare. AFI measurement was repeated at $6^{\text {th }}$ day after hydration therapy by the same sonographer. History of previous oligohydramnios was recorded additionally to cater for effect modification and data was stratified accordingly.

All the collected data was entered into SPSS version 16 and analyzed. Mean and standard deviation was calculated for age, parity and gestational age. The mean difference of amniotic fluid index of the two groups was compared by 
an independent t-test. A p-value of $<0.05$ will be considered statistically significant. Effect modifiers like age, gestational age, parity and history of oligohydramnios were controlled by stratification. Post-stratification independent sample t-test was applied.

\section{RESULTS}

In our study population 114 patients were included with mean age of $27.33 \pm 3.876$ ranged from 20 to 40 years of age, mean AFI score before treatment $3.34 \pm 0.762$ and after treatment 5.61 \pm 1.252. (Table-I)

81 patients $(71.1 \%)$ in our study population were below 30 years whereas 33 patients (28.9\%) were either 30 years or more in age.

When sampled population was stratified by parity, 52 patients (45.6\%) were primiparous and remaining 62 patients $(54.4 \%)$ were multipara. Gestational age in 70 patients $(61.4 \%)$ were below 38 weeks while in rest of $44(38.9 \%)$ it was either 38 weeks or above.

Only 41 (36\%) patients among sampled population had history of oligohydramnios.

Sampled population was equally distributed in two groups. Mean AFI value before treatment in sampled population was $3.35 \pm 0.744$ in oral hydration and $3.33 \pm 0.787$ in intravenous hydration while independent sample test appeared in non-significant results. $(p=0.903)$.

Mean AFI value after treatment in sampled population was $5.53 \pm 0.966$ in oral hydration and $5.68 \pm 1.490$ in intravenous hydration, independent sample test showed non-significant. $(p=0.503)$ difference. (Table-II)

AFI before and after treatment was cross tabulated and resultant difference was significant ( $p$ value $=0.001$ ) on using paired sampled test. (Table-III)

When age group was cross tabulated with difference in AFI results showed up with nonsignificant $p$ value $(p=0.48)$. Mean score for 81 patients below 30 years of age was $-2.32 \pm 1.312$ and for above 30 years patients it was $-2.12 \pm$ 1.409 .

When parity was cross tabulated with difference in AFI results showed up with non-significant $p$ value $(p=0.708)$. Mean score difference for 52 primiparous patients was $-2.21 \pm 1.319$ and for multipara patients it was $-2.31 \pm 1.362$.

When gestation age was cross tabulated with difference in AFI results showed up with nonsignificant $p$ value $(p=0.712)$. Mean score for 70 patients below 38 weeks of gestation age was $-2.30 \pm 1.376$ and for above 38 weeks it was -2.12 \pm 1.286 .

When history of oligohydramnios was cross tabulated with difference in AFI results showed up with non-significant $p$ value $(p=0.541)$. Mean score for 41 patients with history of oligohydramnios was $-2.37 \pm 1.299$.

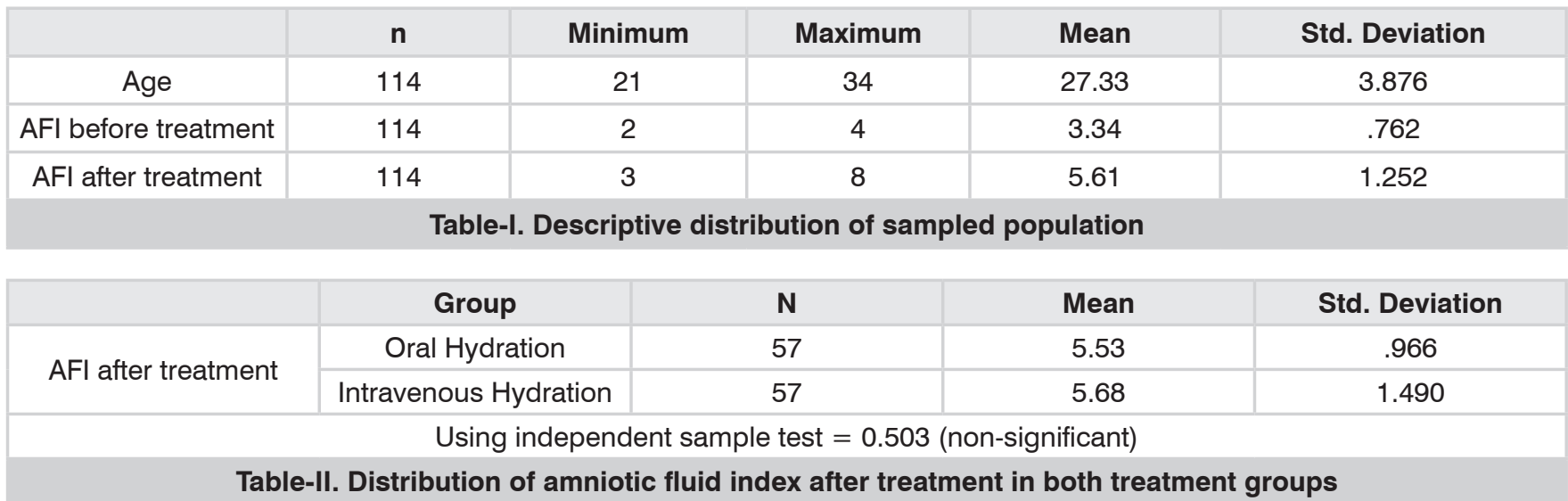




\begin{tabular}{|c|c|c|c|}
\hline & Mean & $\mathbf{n}$ & Std. Deviation \\
\hline AFI before treatment & 3.34 & 114 & .762 \\
\hline AFI after treatment & 5.61 & 114 & 1.252 \\
\hline \multicolumn{2}{|c|}{ Using Paired Samples Test $=0 ~ .001($ significant) } \\
\hline \multicolumn{2}{|c|}{$\begin{array}{c}\text { Table-III. Paired Samples analysis for distribution of amniotic fluid index before and after treatment in both } \\
\text { treatment groups }\end{array}$} \\
\hline
\end{tabular}

\section{DISCUSSION}

In our study, mean amniotic fluid index (AFI) score before treatment was $3.34 \pm 0.762$ and after treatment was $5.61 \pm 1.25$, resultant difference was significant $(p$ value $=0.001)$.

Mean AFI value after treatment in sampled population was $5.53 \pm 0.966$ in oral hydration and $5.68 \pm 1.490$ in intravenous hydration group. Resultant difference was statistically nonsignificant ( $p$ value $>0.05$ )

Our results are comparable with previous studies. In a review, Hofmeyr et al. reported an increase in amniotic volume with oral hydration (MD 1.35, 95\% confidence interval (Cl) 1.43 to 2.60 ) as in our study. However no measureable effects were seen with intravenous isotonic hydration (MD $1.35 .95 \% \mathrm{Cl}-0.67$ to 0.67 ) which contradicts our study. ${ }^{6}$

Shahnazi et al. reported an increase in amniotic fluid index (from 4.70 to $6.25 \mathrm{~cm}$ ) after hydration with one liter of isotonic saline infusion which is similar to our finding. ${ }^{3}$ However our results are contradicted by a study of Momina et al. who compared oral and intravenous hydration in third trimester oligohydramnios and recorded an amniotic fluid index $7.48 \pm 0.303$ in oral group and $5.89 \pm 0.373$ in intravenous group after hydration, concluding that oral maternal hydration is more effective than I/V hydration. ${ }^{4}$

Qureshi and Yusuf studied the effect of intravenous amino acid solution in isolated oligohydramnios and found it to be an effective therapy in raising AFI from mean pre-infusion AFI of $4.7 \mathrm{~cm}$ to $5.8 \mathrm{~cm}$ mean one week post infusion. ${ }^{8}$

Patrelliand collegues studied effects of hydration on oligohydramnios by giving intravenous infusion of $1500 \mathrm{~mL}$ of an isotonic solution per day for 6 days followed by home oral hydration therapy of $1500 \mathrm{~mL} / \mathrm{d}$ subgroup $\mathrm{A} 1$ and 2500 $\mathrm{mL} / \mathrm{d}$ subgroup A2. They reported significant improvement in amniotic fluid index in both subgroups $(P<.001){ }^{7}$

In a study conducted by Nahid lorzadeh and collegues (2008), comparing oral and intravenous fluid therapy, oral hydration group $(p<0.0001)$ had significant increase in AFI, but not in intravenous isotonic or hypotonic group which contradicts our results. ${ }^{10}$

The mechanism responsible for change in amniotic fluid index after maternal hydration and the length of time the increase would persist is still unclear. After 24 weeks of pregnancy fetal urine output is a major contributor to amniotic fluid volume. By increasing intravascular volume and osmolaity, fetal diuresis can be increased. Different clinical studies suggest that the fetus can respond to changes in maternal intravascular volume or osmolality. ${ }^{11,12,13}$

V.T.M. Borges and collegues found out that there was no significant difference between the oral isotonic solution and water in increasing the AF index in women with normohydramnios. Hydration with isotonic solution caused a 10-fold (95\%Cl: $2.09-49.89)$ and water 6 -fold $(95 \% \mathrm{Cl}$ : 1.16-30.95) increase in the AF index. ${ }^{14}$

By decreasing maternal and fetal plasma osmolality, Ross and collegues, observed an increase in amniotic fluid volume. They administered oral water loading $(20 \mathrm{ml} / \mathrm{kg})$ and intravenous 1-deamino-[8-D-arginine] vasopressin $(2 \mu \mathrm{g})$, an antidiuretic, and found maternal plasma osmolality significantly decreased (285 \pm 4 to $265 \pm 4 \mathrm{mOsm} / \mathrm{kg})$ and 
the amniotic fluid index significantly increased $(4.1 \pm 0.6$ to $8.2 \pm 1.5 \mathrm{~cm})$. There was no change in the amniotic fluid index (4.3 \pm 0.4 to $4.7 \pm 0.7$ $\mathrm{cm}$ ) in control patients treated with intravenous hydration. ${ }^{15}$

Umber and chohan studied the effects of acute intravenous maternal hydration on amniotic fluid volume, by infusing 2 liters of $5 \%$ dextrose water in 2 hours. They found a significant $(p<0.05)$ percentage increase in mean AFI i.e, $58.6 \%$ in the oligohydramnios group than the percentage increase of $28.4 \%$ in control group. ${ }^{16}$

In a study by Shripad and collegues, 11 patients were given oral l-arginine and 39 patients received both arginine and intravenous hydration (500 $\mathrm{ml}$ of fructodex and lactated Ringer's solution daily) until the liquor improved significantly. The Improvement in liquor volume was significant after intervention with either or both I-arginine and fructodex infusion $(P<0.0001) .{ }^{17}$

In our study we have found that both oral maternal hydration therapy and intravenous hydration are equally effective in increasing AFI. As there is prolonged hospital admission and risk of complications like thrombophlebitis and fluid overload with intravenous hydration therefore it is not preferred by many patients. So oral maternal hydration can be advised in such cases. Maternal hydration definitely plays an important role in improving amniotic fluid volume in patients with oligohydramnios.

\section{CONCLUSION}

Both treatment modalities i.e. oral maternal hydration and intravenous infusion are effective in terms of improvement of amniotic fluid index but there is no difference in both treatments in pregnant females with isolated oligohydramnios in $3^{\text {rd }}$ trimester at the current sample size.

Copyright@ 23 June, 2019.

\section{REFERENCES}

1. Mires G. Normal fetal development and growth. In: Baker PN, Kenny LC, editors. Obstetrics by Ten Teachers. 19th ed. London: Hodder Arnold 2011:38-47.
2. Kenny LC. Antenatal obstetric complications. In: Baker PN, Kenny LC, editors. Obstetrics by Ten Teachers. $19^{\text {th }}$ ed. London: Hodder Arnold 2011:85-108.

3. Shahnazi M, Meli MS, Hamoony F, Sadrimehr F, Samani $F G$, Koshavar $H$. The effects of intravenous hydration on amniotic fluid volume and pregnancy outcomes in women with term pregnancy and oligohydramnios: A randomized controlled trial. J caring sciences, 2012; $1(3): 123-8$.

4. Momina SB, Akhtar M, Akram M, Yasmeen S. Comparison of the efficacy of oral and intravenous maternal hydration in management of third trimester oligohydramnios. Biomed, 2012; 28: 126-9.

5. Beall MH, Beloosesky R, Ross MG. Abnormalities of amniotic fluid. In:James D, Steer PJ, Weiner CP, Gonik $B$, editors. High Risk Pregnancy Management options. $4^{\text {th }}$ ed. St.Louis: Elsevier 2011:197-203.

6. Hofmeyr GJ, Gulnezoglu AM, Novikova N. Maternal hydration for increasing amniotic fluid volume in oligohydramnios and normal amniotic fluid volume (Review). The Cochrane Collaboration 2012; Issue 2: Art No. CD000134. DOI: 10.1002/14651858.CD000134.

7. Patrelli TS, Gizzo S, Cosmi E, Carpano MG, Gangi SD, Pedrazzi G, et al. Maternal hydration therapy improves the quantity of amniotic fluid and the pregnancy outcome in third trimester isolated oligohydramnios. $\mathrm{J}$ ultras med. 2012; 31(2): 239-44.

8. Qureshi FU, Yusuf AW. Intravenous amino acids in third trimester isolated oligohydramnios. Annals of King Edward Medical University. 2011;17(2):140-.

9. Phelan JP, Ahn MO, Smith CV, Rutherford SE, Anderson E. Amniotic fluid index measurements during pregnancy. J Reprod Med 1987; 32: 601-4.

10. Lorzadeh N, Kazemirad S, Lorzadeh M, Najafi S. Comparison of the effects of oral and intravenous fluid therapy on women with Oligohydramnios. Res. J. Obstet. Gynecol. I(1): 25-29, 2008.

11. Stevens $A D$, Lumbers ER. The effect of maternal fluid intake on the volume and composition of fetal urine. J Dev Physiol 1985; 7: 161-166.

12. Brace RA. Amniotic fluid volume and its relationship to fetal fluid balance: Review of experimental data. Semin Perinatol 1986; 10: 103-112.

13. Lumbers $E R$, Stevens $A D$. Changes in fetal renal function in response to infusions of a hyperosmotic solution of mannitol to the ewe. J Physiol 1983; 343: 439-446. 
14. Borges VTM, Rososchansky J, Abbade JF, Dias A, Peraçoli JC and Rudge MVC. Effect of maternal hydration on the increase of amniotic fluid index. Braz J Med Biol Res 44(3) 2011.

15. Ross MG, Cedars L, Nijland MJ, Ogundipe A. Treatment of oligohydramnios with maternal 1-deamino[8-D-arginine] vasopressin-induced plasma hypoosmolality. Am J Obstet Gynecol. 1996 May; 174(5):1608-13.
16. Umber A, Chohan MA. Intravenous maternal hydration in third trimester oligohydramnios: Effect on amniotic fluid volume. J Coll Physicians Surg Pak. 2007 Jun; $17(6): 336-9$.

17. Hebbar S, Rai L, Adiga P. Maternal hydration and L-arginine supplementation improves liquor volume in patients with decreased liquor and prolongs pregnancy. Med J DY Patil Univ 2014; 7:429-34.

\begin{tabular}{|c|l|l|l|}
\hline \multicolumn{3}{|c}{ AUTHORSHIP AND CONTRIBUTION DECLARATION } \\
\hline Sr. \# & \multicolumn{1}{|c|}{ Author(s) Full Name } & \multicolumn{1}{|c|}{ Contribution to the paper } & Author(s) Signature \\
\hline 1 & Saima Kiran & Concieved main idea. \\
\hline 2 & Adeela Ameen & $\begin{array}{l}\text { Data collection \& correspon- } \\
\text { dence \& manuscript writing. }\end{array}$ \\
\hline 3 & Ayesha Akram & Manuscript writing. \\
\hline 4 & Mahwash Jamil & Data analysis \& Final drafting. \\
\hline
\end{tabular}

